\title{
Vacuum Chamber of the Injector Synchrotron for the Advanced Photon Source
}

\author{
R. Benaroya and R. Dortwegt \\ Argonne National Laboratory \\ Advanced Photon Source \\ Building 362 \\ 9700 South Cass Avenue \\ Argonne, IL 60439
}

ANL/CP- 73089

DE91 011859

Abstract

The 40 chambers of the $368 \mathrm{~m}, 7-\mathrm{GeV}$ injector synchrotron of the Advanced Photon Source are made from $1 \mathrm{~mm}$-thick, 316LN stainless steel tubing. Tubes are colddrawn to an elliptical shape with inside najor and minor axes of $6 \mathrm{~cm}$ and $3.7 \mathrm{~cm}$, respectively. This results in a thin metallic chamber without corrugations, which allows maximum beam space in the magnets and withstands atmospheric pressure. Sections of the chamber are bent to match the radius of cur:ature $(33.3 \mathrm{~m})$ of the beam over the entire effective length of the dipole magnets. A modified orbital welder is used to join sections of tubing. The chambers and the pumping system required to achieve a pressure of $10^{-9}$ Torr are described. A straight section of chamber tubing was tested under extemal pressure up to 60 psig. At 15 psig, the resulting deflection at the minor half axis was $0.2 \mathrm{~mm}$ and a maximum compressive stress of $13500 \mathrm{psi}$ was meastired. Tube deformation remained in the elastic region up to $\sim 38 \mathrm{psig}$.

\section{INTRODUCTION}

The Advanced Ph'ston Source (APS), currently under construction at Argonue, is a synchrotron radiation research facility. It comprises a 200-MeV electron linac whose output is focused on a tungsten target, a $450-\mathrm{MeV}$ positron linac which receives the target positrons, followed by a positron accumulator ring (PAR), a low energy transport line, a 7-GeV injector synchrotron (IS), a tigh energy transport line, and a storage ring which can circulate more than $100 \mathrm{~mA}$ of positrons for times greate- than $10 \mathrm{~h}$, allowing photon beam research at its many experimental beam lines.

The IS (Fig. 1) boosts the beam energy E from $450 \mathrm{MeV}$ to $7 \mathrm{GeV}$. It has a circumference of $368 \mathrm{~m}$ and operates at a repetition rate of $2 \mathrm{~Hz}$. Once each cycle, the positron bunch accumulated in the PAR containing up to $3.6 \times 10^{10}$ positrons is transferred to the IS for acceleration to $7 \mathrm{GeV}$. The rf system has a frequency of $351.93 \mathrm{MHz}$ with a harmonic number of 432 (revolution time is $1.228 \mu \mathrm{s}$ ). The magnetic field is essentially a triangle wave-shape with a dipole peak field of $0.7 \mathrm{~T}$. At this field a 7-GeV beam has a radius of curvalure $\rho=33.3 \mathrm{~m}$. At $7 \mathrm{GeV}$, the beam bunch is extracted and transported to the storage ring for injection.

\footnotetext{
"Work supported by the U.S. Department of Energy. Office of Basic Energy Sciences, under Contrect W-31-109-ENG-38.
}

\section{VACUUM CHAMBER}

\section{A. Configuration}

The IS has forty chambers, connected by circular bellows with Conflat type flanges. There are eight Viton sealed gate valves for isolating sectinns of the ring. Twentyeight of the chambers are normal cells (NC). Figure 2 shows a mock-up of a NC and Fig. 1 (center) indicates the configuration of its components. A NC ( $9.2 \mathrm{~m}$ long) is enciosed within pairs of $\mathrm{H}$-frame dipole magnets, quadrupoles, sextupoles, and correction magnets. Two beam position monitor (BPM) chambers and one bellows are part of the NC. The NC also includes one Conflat type flange at each end and three Conflat type pumping ports. The lower ports are intended for ion pumps ( $30 / / \mathrm{s}$ each) whereas the top port is isolated with a Viton sealed valve for rough punping. Sectors 11 and 12 with only one instead of two quadrupoles each, help form mirror symmetry between the top and lower chambers. Sectors 1-3, 19-23,39, and 40 bave one or two "missing dipoles". They house instead, If cavities, kicker magnets, and septum magnets.

\section{B. Construction}

The NC combines straight and bent tubes. The tubes are made from 316 LN S.S. welded sheets. Blanks of 2.5" 0.D. $x 0.106^{\prime \prime}$ wall $\times 45^{\prime \prime}$ long are cold-drawn in three steps to the correct wall thickness $(1.0 \mathrm{~mm})$ and equivalent perimeter of the ellipse. The final elliptical shape with inside major and minor axes of $6 \mathrm{~cm}$ and $3.7 \mathrm{~cm}$ respectively (Fig. 1) (center) is formed in a turk's-bead roll set. The final tube length is $-340 \mathrm{~cm}$.

The tube wall is sufficiently thin to reduce eddy currents caused by the 2-Hz magnetic field to an acceptable value and thick enough not to require reinforcing ribs. Following a cleaning procedure, the elliptical tubing is annealed at $-1000^{\circ} \mathrm{C}$ in a vacuum fumace. This is a degassing and cleaning operation in addition to stress relief and restoralion of low permeability to $\mu \leq 1.01$. Stress relief is desirable before proceeding with the bending operation.

Only tubes which are placed within the dipoles are bent. Bent tubes match the radius of curvature of the beam to the boundaries of the effective length of the dipole magnels. The remainder of the chambers are stmight. Special care is taken to protect the annealed chambers from contamination especially during the bending operation. After forming and annealling, tubes are curved in a 3-roll bending machine. 


\section{Vecsum Performance}

The assembled chambers are to be baked at $150^{\circ} \mathrm{C}$, mostly to remove water, checked out and stored with a positive nitrogen pressure unil ready to install in the ring. Each quadrant of the ring will be rough pumped with three equally spaced turbomolecular pump stations (1mps). The tmps will be valved off when the two $30 \mathrm{l} / \mathrm{s}$ ion pumps per NC are operated.

With a calculated specific molecular conductance of $13 l \cdot \mathrm{m} / \mathrm{s}$, a specific inner surface area of $1480 \mathrm{~cm}^{2} / \mathrm{m}$ and a thermal desorption rate $q_{t}=2 \times 10^{-12}$ Torr $\ell / \mathrm{cm}^{2} \cdot \mathrm{s}$, the calculated average chamber pressure, $P_{a}$, with no team is $9 \times 10^{-10}$ Torr. However, with beam, initial photo desorption, $\mathrm{q}_{\mathrm{p}}$, dominates the pressure.

We use Sands' expression[2] to determine the mean number of photons $/ \mathrm{e}^{+} \cdot \mathrm{rad}$

$$
\frac{5}{2 \sqrt{3}} \frac{\gamma}{137}=72 \text { photons } / e^{+} \cdot \mathrm{rad}
$$

where the total $\mathrm{e}^{+}$energy in units of rest energy $\gamma=6850 @$ $\mathrm{E}_{\mathrm{av}}=3.5 \mathrm{GeV}$. Given $3.6 \times 10^{10} \mathrm{e}^{+}$/bunch, $1.228 \mu \mathrm{s} / \mathrm{rev}$ and an accelemtion time ratio of 0.5 , we obtain $6.8 \times 10^{18}$ photons/s. With the constant $\mathrm{K}=3.11 \times 10^{-20}$ Torr $/ \mathrm{mol}$ and an assumed initial molecular yield $\eta=2 \times 10^{-3}$ mol/photon where the contribution of each gas species is $\mathrm{H}_{2}=1 \times 10^{-3}, \mathrm{CH}_{4}=8 \times 10^{-5}, \mathrm{CO}=5 \times 10^{-4}$, and $\mathrm{CO}_{2}=2 \times 10^{-4} \mathrm{~mol} / \mathrm{photon}, \mathrm{a} \mathrm{q} \mathrm{p}=9 \times 10^{-10}$ Tor $\mathrm{l} / \mathrm{s} \cdot \mathrm{cm}^{2}$ is obtained. This is a factor of 450 larger than $q_{t}$ and yields a $P_{a v}=4 \times 10^{-7}$ Torr. Beam losses are dominated by scattering due to Bremsstrablung and for $P_{a v}=3 \times 10^{-6}$ Torr, losses are acceptable $(<1 \%)$. The initial $P_{a v}$, then, is not out of line. Even so, the pressure will improve with integrated stored beam $D$.

The rate of improvement depends partly on the critical energy of the photons $e_{c}$ and their angle of incidence $\theta$.

$$
\epsilon_{c}=\frac{2.218 \times 10^{3}\left\langle\mathrm{x}^{3}\right\}_{\mathrm{aq}}}{\rho}=6.07 \mathrm{kev}
$$

where $\left(\mathrm{x}^{3}\right)_{\mathrm{av}}=\int_{0.45}^{7} \frac{\mathrm{z}^{3} \mathrm{ds}}{7-0.45}=91.6 \mathrm{Gev}^{3}$

and $\theta=42 \mathrm{mrad}$

The Bessy[3] storage ring experience can be expressed empirically as $\eta=5 \times 10^{-5} \mathrm{D}^{-2 / 3}$, and is a conservative approach that could be used to estimate $D$ in $A-h$ when the pressure to attain is set at, say, $7 \times 10^{-9}$ Torr. Since this is a factor of 5 ? improvement over the initial pressure $\eta \equiv 3.5 \times 10^{-5} \mathrm{~mol} / \mathrm{photon}$ then,

$$
D=\left(\frac{5 \times 10^{-5}}{\eta}\right)^{3 / 2}=1.7 \mathrm{~A}-\mathrm{h}
$$

\section{Serucural Peroormance of Elliptical Thinin}

A two-dimensional stress analysisf 4 ] ind icates that the stmetural performance of the elliptical qube is limised hy the bending stress. When overloaded, bending stress exceeds the yield point of the material before the tube becomes unstable and buckles. With an external pressure of $15 \mathrm{psig}$, the maximum bending stress at the major axis is 14400 psi for a $0.97 \mathrm{~mm}$ wall. The corresponding defleclion across the minor axis is $0.51 \mathrm{~mm}$. Since the anticipated maximum stress levels approach $1 / 2$ the yield strength of the tube (minimun of $30000 \mathrm{psi}$ ), a tes! :yas performed to verify the stress analysis. The test also serves to provide tube performance data under overload conditions allowing determination of tube safery factor for the vacuum condition.

A section of elliptical tube $3.35 \mathrm{~m}$ in length was prepared by compressing a 2 -in. O.D. 304 S.S. ube of circular cross-section. The resulting oval tute approximates the true elliptical cross-section of the chamber lubing. The difference in radius between the compressed oval tube and the true elliptical shape is less than $0.4 \mathrm{~mm}$ over most of the lube. The elliptical tube was fitted with two vertical reference pins protruding internally on the minor axis near the nidpoint of the $3.35 \mathrm{~m}$ length for sighting the deflection under load. The pins are visible from the ends of the tube and any movement was observable from a distance. Strain gauges were placed mid tube also, along the outside perimeter. The tube was enclosed within a slightly shorter 3.5-in. diameter pipe and welded shut against the tube at the ends of the pipe. The electrical connections to the strain gauge were accessed through a feedthrough. The pipe was filled with distilled water and pressure was varied with a hydraulic pump. The pressure was raised in steps of 5 psi and back to 0 psig until 60 psig was reached.

At 15 psig the measured deflection across the minor axis was $0.41 \mathrm{~mm}$ and the maximum measured bending stress was 13500 psi. Permanent deformation occurred between 35 and 40 psig. Therefore, under vacuum, the tube is operating with a safety factor $>2.5$. Thus, the experimental results are more favorable than the analysis, indicating that the elliptical chambers are structurally sound for vacuum operations.

\section{UI. ACKNOWLEDGEMENTS}

The authors wish to thank R. C. Niemann for his constant support and many discussions; A. Salzbrunn for the preparation of the manuscript; and J. Peak for editing.

\section{REFERENCES}

[1] "7-GeV Advanced Photon Source Conceptual Design Report", ANL-87-15, April 1987.

[2] M. Sands, SLAC-121, p. 117, Addendum, May 1979.

[3] L. Schulz, et al., AIP Conf. Proc. No. 171, pp. 116123, 1988.

[4] J. Howell, "Analysis of the IS Chamber Tube Loading due to Extemal Pressure," Advanced Photon Source note, Oct. 1990. 